\title{
Cell Culture
}

\author{
MIKE BOULTON \\ London
}

Cell or tissue culture is considered a somewhat esoteric subject and its disciples are viewed by many people as a coven of witches placing ingredients into a large cauldron and achieving a magical response. I would like to persuade the reader that cell culture is not only an interesting subject but is also a useful tool in biological research. At this point it should be emphasised that cell culture is a technique and not a discipline like biochemistry or cell biology. In fact cell culture provides an in vitro model which can then be modulated and studied by the biochemist, cell biologist or molecular biologist.

What is cell culture and why do we need it? Cell or tissue culture is defined as the growth of a specific cell type under in vitro conditions. ${ }^{1}$ This is distinct from organ culture in which whole or parts of organs are maintained in vitro for short periods of time. ' Cell culture allows: the isolation of a pure cell population, the amplification of tissue (cells divide in culture and thus numbers increase), the study of the normal physiology of a single cell type without masking effects from other cell types, and examination of the putative mechanisms involved in pathological processes.

Three objectives need to be achieved in order for cell culture of a particular cell type to be successful:

(1) Can that cell type be isolated and grown in culture?

(2) Do the resultant cells function (ie do they retain all or some of their in vivo characteristics)?

(3) Can they be used to study cell physiology and pathological processes?

The first objective is the most difficult for the person involved in cell culture. Careful dissection is required to expose the required cell type. Once exposed the cells need to be removed, usually mechanically or by enzyme treatment, avoiding contamination by the unwanted cell types. Isolated cells are placed in tissue culture flasks containing growth medium. Since the growth of most cell types, with the exception of transformed or cancerous cells, is attachment dependent, plastic flasks often need to be coated with a suitable substrate (eg gelatin, collagen, laminin, fibronectin poly-l-lysine or mixtures thereof) in order to facilitate attachment. The composition of the growth medium is also important, each cell type has its own optimum requirement of amino acids, carbohydrates, inorganic salts, growth factors and the addition of serum components. Only when the balance is correct will the cells attach and proliferate. Even when these criteria are met the second objective is not always fulfilled and often modifications need to be made to this 'soup' in order for the cells to manifest their in vivo functions.

Cell cultures can only be derived from tissues which retain the capacity to divide. In the eye these are many; corneal epithelium ${ }^{2}$ and endothelium, ${ }^{3}$ fibroblasts, ${ }^{+}$vascular endothelial cells and pericytes, ${ }^{+}$trabecular meshwork cells, ${ }^{5}$ lens epithelium, ${ }^{6}$ retinal pigment epithelium, ${ }^{7-10}$ astroglia, ${ }^{11}$ choroidal cells ${ }^{12}$ and others. Unfortunately for the cell culturist the neuronal cells (ganglion, amacrine, bipolar, horizontal and photoreceptor cells) lose their ability to divide early in life and thus cannot be grown in culture. An alternative approach in these latter cell types has been to grow cells

From: Department of Clinical Ophthalmology, Institute of Ophthalmology, London.

Correspondence to: Dr Mike Boulton, University Department of Ophthalmology, Manchester Royal Eye Hospital, Oxford Road, Manchester M13 9WH. 
from embryonic retinae,,$^{13,14}$ but the resultant cell populations tend to remain undifferentiated and fail to fulfil points (2) and (3) of the objectives.

Since so many different ocular cell types can be grown in culture I shall illustrate one cell type from one species, the human retinal pigment epithelium (RPE). The retinal pigment epithelium is a monolayer of pigmented cells located between the photoreceptors and the choroid and is essential for visual function in that it forms the outer blood-retinal interface, it maintains the visual cycle through transport and esterification of vitamin $\mathrm{A}$, it controls the environment in the sub-retinal space through transepithelial transport, it phagocytoses the spent discs of photoreceptor outer segments and digests them by means of hydrolytic enzymes contained within lysosomes, it is responsible in part for the production of the interphotoreceptor matrix and Bruch's membrane and it is able to neutralise damaging free radicals. ${ }^{15}$ These cells are thought not to divide in the normal eye following maturity but do have the capacity to divide when traumatised as in retinal detachments ${ }^{16}$ and after laser photocoagulation. ${ }^{17}$

\section{Isolation and Growth Isolation}

Human eyes need to be received in the laboratory within 72 hours post-mortem. The anterior segment is removed just below the ora serrata and discarded. The vitreous and retina are then removed without damaging the RPE or Bruch's membrane (an intact Bruch's membrane is essential to avoid contamination with choroidal cells). The RPE cells can then be detached either mechanically or more commonly be enzyme treatment. ${ }^{18}$ In the latter technique the eye cups are filled with either $0.25 \%$ trypsin $^{8,9}$ (a peptidase which detaches the cells but does not digest Bruch's membrane) or dispase ${ }^{10}$ (a neutral protease) and incubated at $37^{\circ} \mathrm{C}$ for one hour. The solution is agitated to detach cells from Bruch's membrane and removed into serum containing culture medium (serum inhibits any further enzyme activity on the cells). In some instances, particularly with eyes from young donors, the enzyme procedure will need to be repeated a further one or two times. An alternative approach which prevents contamination of other cell types from the cut edges of the eye and the optic nerve head and allows isolation of RPE cells from discrete areas of the retina is the use fo the 'cylinder technique'. ' This involves dissecting the eyecup devoid of retina and vitreous into segments. Stainless steel cylinders are placed on the RPE and sealed in place with vaseline. The area of RPE contained within each cylinder is then treated with trypsin as described above. The advantage of this technique is that RPE cells can be isolated from different areas of the retina or from small portions of tissue such as biopsies. Once the maximum number of cells have been isolated they are pelleted by centrifugation and resuspended at an appropriate concentration $\left(2 \times 10^{4}\right.$ cells $\left./ \mathrm{ml}\right)$ in growth medium and placed in $17 \mathrm{~mm}$ uncoated plastic multiwells which are incubated in a $37^{\circ} \mathrm{C} \mathrm{CO}_{2}$ incubator in an atmosphere of $5 \% \quad \mathrm{CO}_{2} / 95 \%$ air. A variety of commerically available growth media can be used to grow these cells. A typical medium of choice in many laboratories is Nutrient Mixture Ham's F10 supplemented with $20 \%$ foetal calf serum, $0.4 \%$ glucose and antibiotics. ${ }^{8.9}$ Other laboratories have employed media with reduced serum concentrations but have compensated by the addition of growth factors such as insulin, transferrin, hydrocortisone, putrescine and linoleic acid. ${ }^{10}$

Similar techniques to those described above can be used to isolate RPE cells from the adult eyes of large animal species (monkeys (Boulton, unpublished), cows,${ }^{19}$ pigs, ${ }^{20}$ dogs (Cabral, unpublished), cats ${ }^{21}$ or rabbits $^{22}$ ) but more complicated procedures are required for the isolation of RPE cells from rats, mice and chick embryos whose eyes are very small. ${ }^{8.23}$

\section{Growth}

Immediately after being placed in growth medium the human RPE cells exhibit a rounded profile (Fig. 1a) but within 2 to 7 days a proportion of the cells will have attached and demonstrate a flattened morphology (Fig. 1b). Between 1 and 14 days following attachment a proportion of the cells will begin to divide. At this stage three distinct cell types can be observed: 

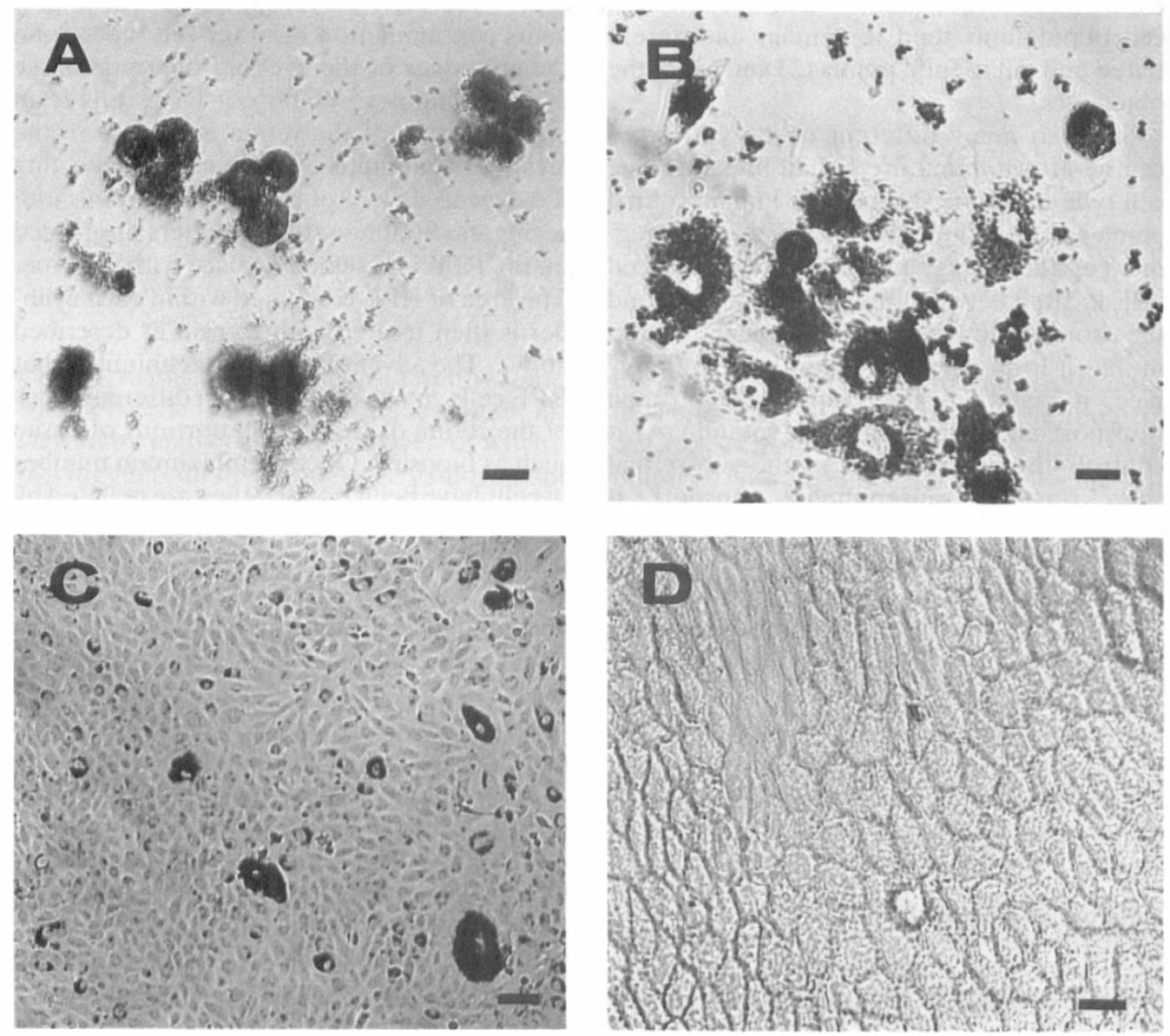

Fig. 1. Photomicrographs of different stages of primary cultures of human retinal pigment epithelial cells derived from a 48-year old donor. (a) immediately following isolation, (b) 14 days after isolation showing attachment of cells, (c) 27 days after isolation showing large heavily pigmented cells (arrowed) interspersed with smaller less-

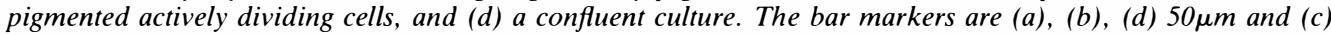
$100 \mu \mathrm{m}$.

(1) occasional large highly pigmented multinucleate cells,

(2) pigmented cells remaining at the attachment stage but not dividing

(3) actively dividing cells (Fig. 1c).

The actively dividing cells will continue to proliferate until a confluent monolayer of non- or poorly pigmented hexanocuboidal cells (Fig. 1d) all of which are cytokeratin positive. ${ }^{24}$ This depigmentation is ascribed to the dilution of pigment granules amongst daughter cells. ${ }^{7,25}$ The lag period between cell attachment and division, the proportion of the three cell types and the rate of proliferation are dependent on the donor age. ${ }^{7,26} \mathrm{RPE}$ cells from the eyes of young donors exhibit a shorter lag period, a greater number of actively dividing cells and a faster proliferation rate than eyes from older donors.

The primary confluent monolayers can be readily sub-cultured by detaching the cells with $0.25 \%$ trypsin and dispersing the cells in a larger number of flasks thereby increasing the quantity of tissue. The cells can be subcultured as many as 20 times before the cells reach a 'crisis-period' and fail to divide. ${ }^{26}$

\section{Functional Status}

Having successfully obtained human RPE cultures the next step is to determine to what 
extent these cells retain the morphological and biochemical features demonstrated in vivo and what modifications, if any, need to be made to enhance the expression of in vivo characteristics in cultured cells.

\section{Morphology}

Primary RPE cultures have many ultrastructural similarities to their in vivo counterparts: the cells are polarised demonstrating apical microvilli, junctional complexes, basal nuclei and large numbers of cytoplasmic organelles (Fig. 2). The two obvious differences are, firstly a reduction in the degree of invagination of the basal plasma membrane and secondly an almost complete disappearance of melanin and lipofuscin granules. These two differences are perhaps not surprising. The cells are grown on an impermeable plastic substrate and thus receive their nutrients from the apical surface only. This negates the need for a increased area of basal plasma membrane for the absorption of nutrients. The inability of cultured adult human cells to resynthesise either melanin or lipofuscin granules is predictable since melanogensis only occurs in RPE cells during a brief window of embryogenesis ${ }^{27}$ and lipofuscin results from the lifelong accumulation of incompletely degraded waste products. ${ }^{28}$

Secondary cultures, in contrast to primary cultures, show some degree of dedifferentiation. ${ }^{18}$ The cells are very flat with cross-sectional diameters of up to $80 \mu \mathrm{m}$ and in some instances the cells overgrow each other to form multilayers. Junctional complexes are rare and the number of microvilli greatly

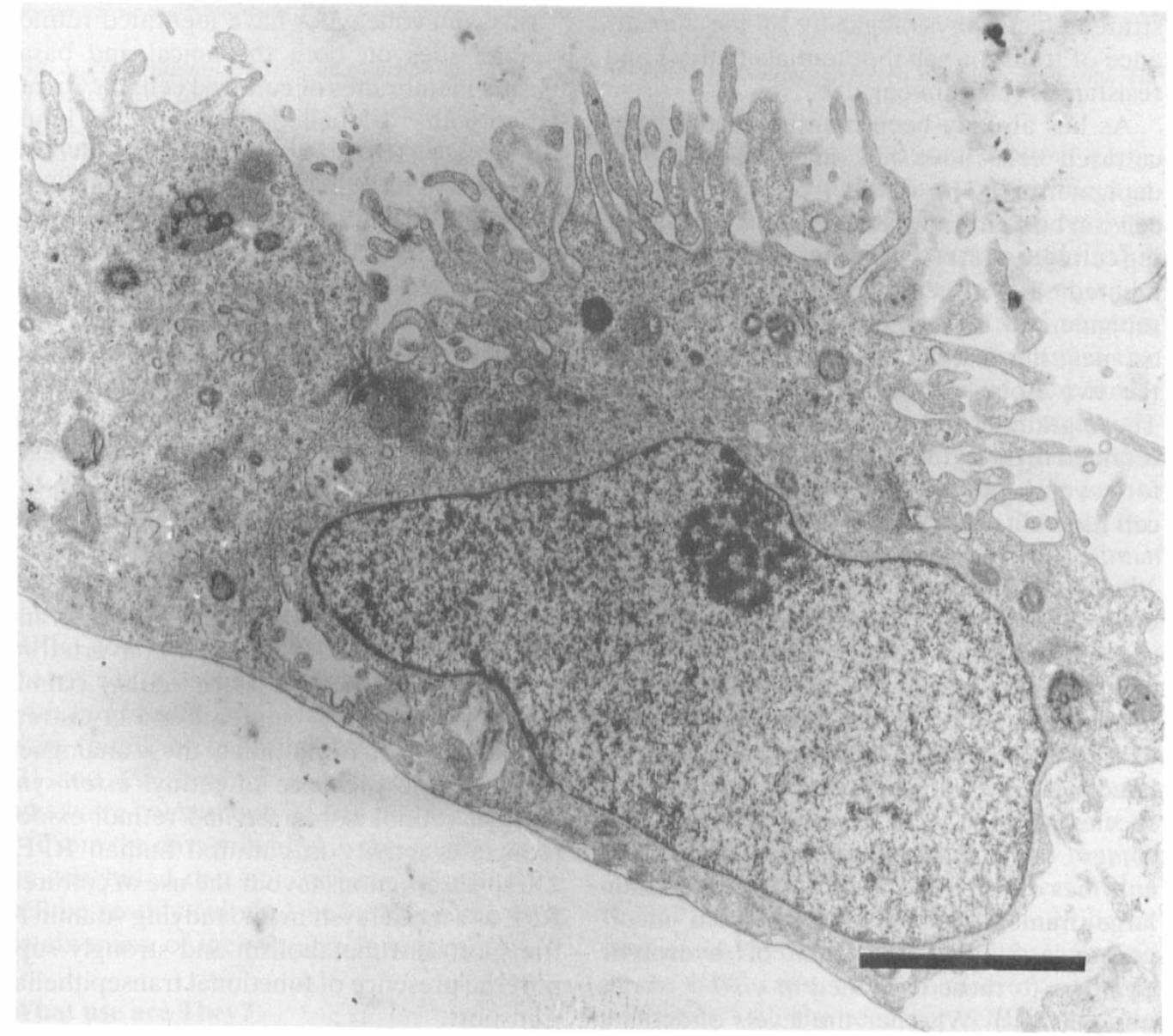

Fig. 2. Transmission electron micrograph of human RPE in primary culture. The bar marker is $2 \mu m$. 
reduced as are the numbers of intracytoplasmic organelles.

In order to overcome these limitations a number of modifications can be made to the culture system. The introduction of permeable support membranes precoated with laminin or collagen as a substrate on which to grow the cells together with the a low calcium growth factor enriched medium has significantly improved the morphological and biochemical characteristics of cultured RPE. ${ }^{29}$ Unlike the impermeable plastic of the flasks on which the cells are normally grown, the permeable membranes allow culture medium to bathe both the apical and basal surface of the cells. This technique produces RPE cells with well developed apical microvilli, apicolateral junctions and basal infoldings characteristic of the tissue in vivo. The high degree of polarisation in this system can be demonstrated electrophysiologically by the appearance of transepithelial potentials $(5 \mathrm{mV})$ and resistances $\left(50 \mathrm{ohm}-\mathrm{cm}^{2}\right) .{ }^{29}$

As has already been mentioned that subcultured cells have few microvilli and are depigmented. The number of microvilli per cell can be significantly increased by challenging cultures with rod outer segments. ${ }^{30}$ Depigmented RPE cells can be 'artificially' repigmented by feeding them either melanosomes, lipofuscin granules or a mixture of the two isolated from human RPE cells. ${ }^{25}$ These granules are readily ingested and are retained in the cytoplasm of non-dividing cells for several months with no apparent loss of cell function.

\section{Biochemisty}

Once the optimum growth conditions of these cells have been defined it is possible to demonstrate that cultured human RPE retain many of their in vivo biochemical capabilities. Cultured human RPE cells readily ingest isolated rod outer segments from a variety of species (Fig. 3), and the resultant phagosomes are degraded by the hydrolytic enzymes of the RPE ${ }^{30}$ Cultured cells contain large numbers of lysosomes which incorporate a similar spectrum of hydrolytic enzymes to those identified in vivo (Cabral, unpublished). Whether the levels of activity of these enzymes remains the same as in vivo remains to be determined but studies on dog RPE have demonstrated a decrease in overall activity in cultured RPE when compared to freshly isolated dog RPE. Interestingly, although the activities in cultured cells is reduced, the topographic distribution of acid phosphatase in fresh dog RPE is also manifest in primary cultures isolated from different areas of the fundus (Cabral, unpublished). However, this variation is not apparent in subcultured cells. Using permeable membranes it has been possible to show that the cells are capable of releasing hydrolytic enzymes from both surfaces and that the type and activities of enzymes released are different between the apical and basal surface. ${ }^{31}$ Whether this observation is comparable in vivo is open to debate, some workers claim that active lysosomes are released from the RPE in vivo while others fail to support this claim. ${ }^{32,33}$

Bok and colleagues have identified retinol binding sites on both the apical and basal plasma membranes of cultured cells. ${ }^{10.29}$ Incubation with ${ }^{125}$ I-labelled plasma retinol binding protein (RBP) expressed a high level of receptors to RBP in first subculture cells with the basally oriented receptors predominating over those on the apical surface. Furthermore, cultured human RPE can internalise ${ }^{3} \mathrm{H}$-retinol carried by RBP resulting in synthesis of labelled retinyl palmitate. When ${ }^{3} \mathrm{H}$-retinol-RBP is applied to 'tight' monolayers of RPE grown on permeable membranes transcellular transport occurs only in the basal to apical direction. Using interphotoreceptor matrix retinoid binding protein (IRBP) as a carrier for the specific delivery of all-trans retinol to the apical side of the monolayer demonstrated internalisation of all-trans retinol which was subsequently converted to three primary species: 11-cis-retinyl palmitate, all-trans-retinyl palmitate and 11-cis-retinaldehyde. The formation of these analogues points to the presence of retinyl ester synthetase, retinol isomerase and retinol oxidoreductase activity in cultured human RPE. These observations favour the use of cultured RPE as a model system for studying vitamin A transport and metabolism and strongly support the presence of functional transepithelial transport.

The interphotoreceptor matrix (IPM) of 


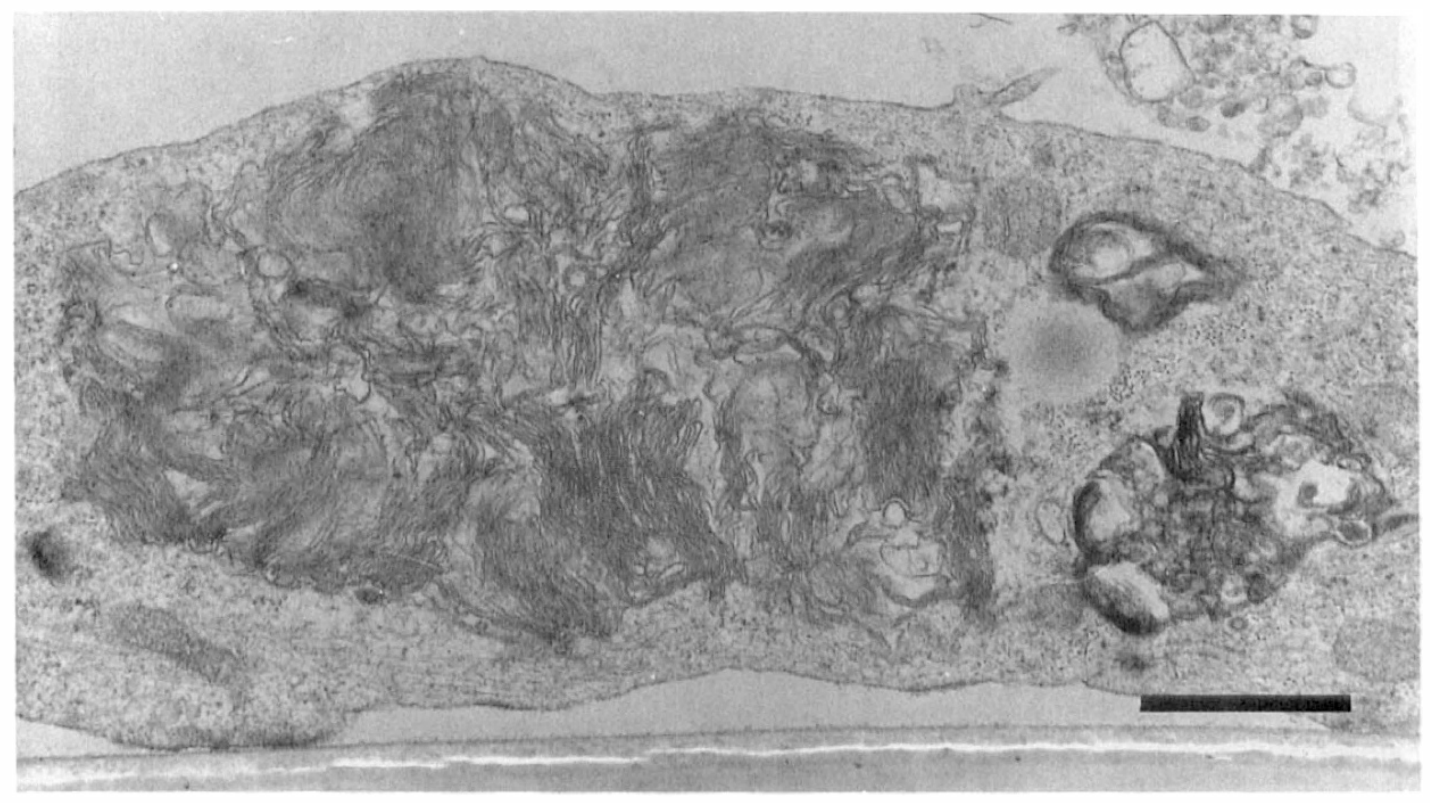

Fig. 3. Transmission electron micrograph of sub-cultured human RPE showing ingested rod outer segments. The bar marker is $1 \mu \mathrm{m}$.

mammalian eyes contains high concentrations of glycosaminoglycans. Cultured human RPE cells have the capacity to synthesise and secrete distinct classes of glycosaminoglycans. ${ }^{12}$ These can be identified as hyaluronic acid, chondroitin sulphate and dermatan sulphate which relate in part to the constituents of human IPM. The lack of a close correlation between the glycosaminoglycans from cultured RPE and extracts of human IPM is possibly due to one of two factors; glycosaminoglycans are also produced by other cell types bordering the IPM space and the possible modification of glycosaminoglycans after their secretion into the IPM space. Human RPE cells also produce an extracellular matrix which becomes increasingly prominent with time in culture. ${ }^{34}$ The components of this were found to consist of collagen types I, II, III and IV, laminin and fibronectin all of which are constituents of Bruch's membrane.

From the data provided in this section it can be concluded that not only can human RPE cell be readily cultured but at the same time retain many of their in vivo functions.

What use are They?

Cultured RPE provide an excellent model system with which to study: normal physiology, ocular diseases and ageing mechanisms. Studies on the physiology are really an extension of the previous section and the following section will concentrate on ocular pathology. Of the common general receptor dystrophies, it is only in choroideremia that the RPE has been recognised as the primary site of disease. There are however, many diseases in which abnormalities are observed in the RPE but these are probably secondary to the initial cause. Certainly there is strong evidence that abnormal handling of phagosomal material by the RPE occurs in fundus flavimaculatis and Best's disease. ${ }^{18}$ There is considerable suport for the concept that ageing of the RPE is an important step in Drusen formation and macular problems in age related diseases. ${ }^{35}$ In most disorders falling within retinitis pigmentosa it is believed that the receptors are the first to die. However, it is conceivable that receptor cell death may be caused by a primary metabolic defect within the RPE. In Refsum's syndrome the evidence implies that abnormal storage of phytanic acid in the RPE causes disturbance of exchange processes with the receptor cells and consequent receptor death. ${ }^{36}$ Histopathology of 
some eyes from retinitis pigmentosa sufferers and a donor with Lawrence-Moon-Biedl syndrome have demonstrated an exaggerated accumulation of lipofuscin. ${ }^{37}$ In the RCS rat failure of phagocytosis by the RPE results in degeneration of the outer retina, and yet, apart from the absence of phagosomes the RPE appears quite normal. ${ }^{38}$ It is evident that the possibility of primary metabolic defects in some types of retinitis pigmentosa must not be excluded.

In attempting to understand the mechanisms involved in ocular pathologies cultured RPE can be investigated by:

(a) comparing cell function between RPE cultured from normal and diseased eyes,

(b) modifying cell behaviour to simulate disease,

(c) examining external factors (ie light) on cell function,

(d) studying cell-to-cell interactions

(e) testing the efficacy of pharmacological agents

(d) in vitro and in vivo cell replacement and (f) molecular biology.

Due to the introduction of national retinitis pigmentosa eye donor schemes the majority of in vitro studies on diseased tissue have concentrated on retinitis pigmentosa and related dystrophies. RPE cultures derived from both normal donors and donors with retinitis pigmentosa have been shown to exhibit similar growth and phagocytic capabilities. ${ }^{930}$ However, there is some evidence that dystrophic cultures from human donors exhibit abnormal glycosaminoglycan production, ${ }^{12}$ basement membrane production ${ }^{39}$ and HLA-DR antigen expression. ${ }^{40}$ The import of these results will only become apparent when cultures from sufficient numbers of donors have been examined.

It is possible to produce ageing changes in the RPE in vitro which are similar to those seen in vivo. Cultured human RPE cells fed daily doses of rod outer segments for periods of up to three months are capable of developing intracellular autofluorescent inclusions similar to lipofuscin (Fig. 4). ${ }^{41}$ Using this model system it is possible to examine factors which may modulate lipofuscin formation (ie antioxidants and light). To date the only anti- oxidant examined in this system is vitamin $\mathrm{E}$ which did not appear to affect granule formation. ${ }^{41}$ Sidikaro and co-workers have shown that this accumulation of 'lipofuscin-like' material was significantly increased if the outer segments were exposed to UV-B irradiation prior to ingestion. ${ }^{42}$ It has also been claimed that sub-RPE debris and Drusen-like nodules can be prodcued in this test system which compare morphologically with those observed in vivo. ${ }^{42}$ It thus appears that for the first time we have a simple model in which to investigate ageing processes within the RPE without interference from other cell types.

Light damage in the RPE can be investigated by exposing primary cultures which retain some pigment granules or repigmented cultures to different light regimes. Lawill has investigated light damage in primary bovine RPE and demonstrated a number of wavelength dependent pathological effects. ${ }^{43}$ However, human RPE may react differently since these cells contain not only melanosomes but also lipofuscin and melano/lipofuscin complexes. This system could also allow investigation of free radical production under low light exposures.

Cultured RPE cells from a number of animal species have been used as donor tissue in retinal transplantation studies. ${ }^{22.44 .45}$ The advantage of using cultured cells is that rejection can be avoided by growing RPE cells from a retinal biopsy and following recovery of the biopsy site inject them back into a different region of the same eye.

There is now strong evidence to suggest that RPE cells can somehow modulate the retinal vessels. ${ }^{46}$ In vitro studies have supported this observation and shown that RPE cells produce diffusible factors which can either stimulate or inhibit capillary basement membrane breakdown, and the migration and proliferation of retinal microvascular cells. ${ }^{47,48}$ These studies are particularly important in understanding retinal neovascularisation in proliferative retinopathies. In all the above studies pharmaceutical agents can be examined either for their potential retinal toxicity and their ability to modulate disease processes.

Molecular biology is a further technique 


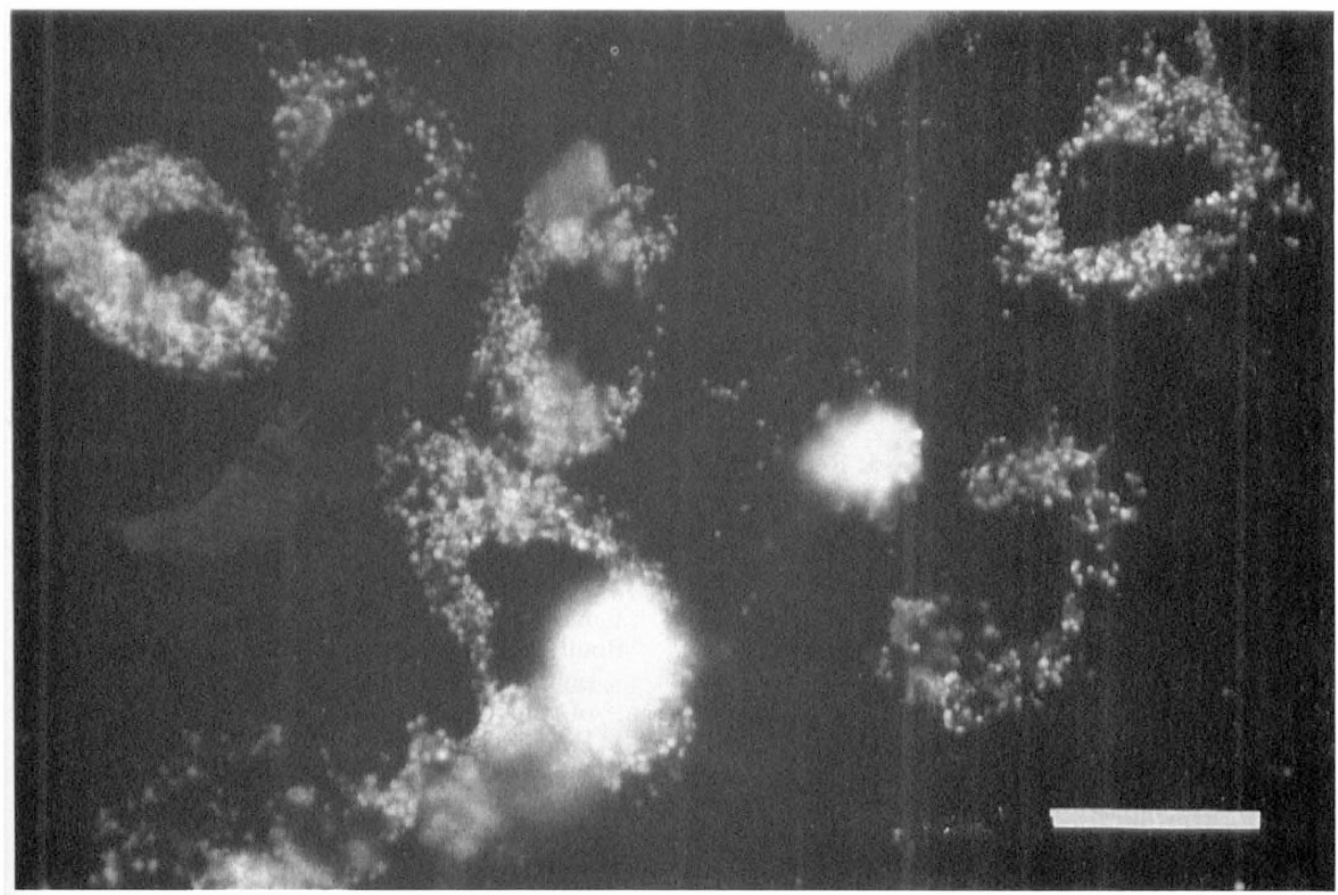

Fig. 4. Fluorescence photomicrograph showing autofluorescent granules in cultured human RPE following three months of daily challenge with rod outer segments. The bar marker is $50 \mu \mathrm{m}$.

which can be applied to cultures. RPE cells can be isolated from eyes with inherited retinal dystrophies and the quantity of tissue amplified until enough is available to obtain genetic maps of the cells. Such maps can then be compared with normal cells in the hope of identifying the genetic defect in particular diseases.

In conclusion, cell culture can offer a major contribution to the understanding of cell physiology, disease and ageing processes. Tissue can be amplified, it is a pure cell type, it obviates the use of large numbers of animals and retains the defective gene in cells isolated from donors with inherited disease. There are however, potential limitations to cell culture: the cells are not in their normal environment, stimuli from other cell types are absent and care has to be taken in relating in vitro findings to the in vivo situation. Although this paper has concentrated on the RPE, much work has been carried out on other ocular cell types, such as corneal epithelium and endothelium, fibroblasts, vascular endothelial cells and pericytes, trabecular meshwork cells, lens epithelium, astroglia, choroidal cells and others. Furthermore, non-ocular cell types such as hybridoma cells for the production of monoclonal antibodies and transformed cells for the study of mutagenesis are also important in ophthalmic research.

The author is indebted to Fight for Sight for financial support and grateful to Professor Alan Bird for many helpful comments in the preparation of this manuscript.

\section{References}

${ }^{1}$ Paul J: Cell and Tissue Culture, 1975. Edinburgh, London and New York, Churchill Livingstone Press.

${ }^{2}$ Ebato B, Friend J, Thoft R: Comparison of central and peripheral human corneal endothelium in tissue culture. Invest Ophthalmol Vis Sci 1987, 28: 1450-6.

${ }^{3}$ Nevo Z, Gonzalez R, Gospodarowicz D: Extracellular matrix $(\mathrm{ECM})$ proteoglycans produced by cultured bovine corneal endothelial cells. Connect Tissue Res 1984, 13: 45-57.

${ }^{4}$ Wong HC, Boulton ME, Marshall J, Clark P: Growth of retinal capillary endothelia using pericyte conditioned medium. Invest Ophthalmol Vis Sci 1987, 28; 1767-75.

${ }^{5}$ Grierson I, Robins E, Unger W, Miller L, Ahmed 
A: The cells of the bovine outflow in tissue culture. Exp Eye Res 1985, 40; 35-46.

${ }^{6}$ Beebe DC and Feagans DE: A tissue culture system for studying lens cell differentiation. Vis Res 1981 , 21: 113-8.

${ }^{7}$ Flood MT, Gouras P, Kjeldbye H: Growth characteristies and ultrastructure of human retinal pigment epithelium in vitro. Invest Ophthalmol Vis Sci 1980, 19: 1309-20.

${ }^{8}$ Edwards RB: Culture of mammalian retinal pigment epithelium and neural retina. In Visual Pigments and Purple Membranes (L Packer and N Kaplan, eds) New York Academic Press. Methods in Enzymology 1981, 81: 39-43.

${ }^{9}$ Boulton ME, Marshall J, Mellerio J: Retinitis pigmentosa: A preliminary report on tissue culture studies of retinal pigment epithelial cells from eight affected human eyes. Exp Eye Res 1983, 37: 307-13.

${ }^{10}$ Pfeffer BA, Clark VM, Flannery JG, Bok D: Membrane receptors for retinol-binding protein in cultured human retinal pigment epithelium. Invest Ophthalmol Vis Sci 1986, 27: 1031-40.

${ }^{11}$ Burke JM and Foster SJ: Culture of adult rabbit retinal glial cells: methods and cellular origin of explant outgrowth. Curr Eye Res 1984, 3: 1169-78.

${ }^{12}$ Edwards RB: The use of tissue culture techniques to study normal and diseased retinal pigment epithelium. In Retinal Research (N Osborne and G Chader, eds) Pergamon Press, Vol. 2, 1983, 51-66.

${ }^{13}$ Clayton RM, de Pomerai DI, Pritchard DJ: Experimental manipulation of alternative pathways of differentiation in cultures of embryonic chick neural retina. Develop Growth Diff 1977, 19: 319-28.

${ }^{14}$ Vollmer G, Layer PG, Grierer A: Reaggregation of embryonic chick retina cells: pigment epithelial cells induce a high order of stratification. Neurosci Lett 1984, 48: 191-6.

${ }^{15}$ Zinn K and Marmor MF: The Retinal Pigment Epithelium. 1979, Cambridge, Mass. and London; Harvard University Press.

${ }^{16}$ Anderson D, Stern W, Fisher S, Erikson P, Borgula $\mathrm{G}$ : The onset of pigment epithelial cell proliferation after retinal detachment. Invest Ophthalmol Vis Sci 1981, 21: 10-16.

${ }^{17}$ Marshall $\mathrm{J}$ and Mellerio J: Laser irradiation of retinal tissue. B Med Bull 1970, 26: 156-60.

${ }^{18}$ Boulton $\mathrm{ME}$ and Marshall J: A mechanistic approach to the inherited retinal dystrophies and the role of tissue culture as an investigative probe. In Heredity and Visual Development (J Sheffield and SR Hilfer, eds), Springer Verlag, 1985, 115-170.

${ }^{19}$ Basu PK, Sarkar P, Menon I, Carre F, Persad S: Bovine retinal pigment epithelial cells cultured in vitro: growth characteristics morphology, chromosomes, phagocytosis ability, tyrosinase activity and effect of freezing. Exp Eye Res 1983, 36: 671-83.

21) Lane CM, Boulton ME, Bird AC, Marshall JM: Growth of pure cultures of retinal pigment epi- thelial cells using chorioretinal biopsies in the miniature pig. Exp Eye Res 1988, 46: 813-17.

${ }^{21}$ Stramm LE, Haskins ME, Govern MM, Aguirre GD: Tissue culture of cat retinal pigment epithelium. Exp Eye Res 1983, 36: 91-101.

${ }^{22}$ Lopez R, Gouras P, Brittis M, Kjeldbye H: Transplantation of cultured rabbit retinal pigment epithelium to rabbit retina using a closed-eye method. Invest Ophthalmol Vis Sci 1987, 28: 1131-7.

${ }^{2.3}$ Crawford B: Cloned pigmented epithelium. The role of microfilaments in the differentiated of cell shape. J Cell Biol 1979, 81: 301-5.

${ }^{24}$ McKechnie NM, Boulton ME, Robey H, Savage F; Grierson I: The cytoskeletal elements of human retinal pigment epithelium in vitro and in vivo. $J$ Cell Sci 1988 (in press).

${ }^{25}$ Boulton ME and Marshall $\mathrm{J}$ : Repigmentation of human retinal pigment epithelial cells in vitro. Exp Eye Res 1985, 41: 209-18.

${ }^{26}$ Boulton ME, Marshall J, Mellerio J: Human retinal pigment epithelial cells in tissue culture: a means of studying inherited retinal disease. In Genetic Eye Diseases: Retinitis Pigmentosa and Other Inherited Eye Disorders (E Cotlier, IH Maumanee, ER Berman, eds), Alan R. Liss Inc., 1981, Vol. 18: 101-18.

${ }^{27}$ Mann I: The Development of the Human Eye. 1969, BMA. London.

${ }^{28}$ Feeney-Burns L: The pigments of the RPE. In Current Topics in Eye Research (JA Zadunaisky and H Davson, eds) Academic Press, New York. 1980, Vol. 11, 119-78.

${ }^{29}$ Flannery JG, Pfeffer BA, Bok D: Transepithelial transport of retinol by monolayers of human RPE in vitro. Invest Ophthalmol Vis Sci 1986, 27 (suppl): 294.

${ }^{311}$ Boulton ME, Marshall J, Mellerio J: Retinitis pigmentosa: a quantitative study of the apical membrane of normal and dystrophic human retinal pigment epithelial cells in tissue culture in relation to phagocytosis. Graefe's Arch Clin Exp Ophthalmol 1984, 221: 214-29.

${ }^{31}$ Wilcox DK: Vectoral accumulation of acid hydrolases from polarized RPE in culture. Invest Ophthalmol Vis Sci 1987, 29 (suppl): 92.

${ }^{32}$ Farkas TG, Sylvester V, Archer D: Histochemistry of Drusen. Am J Ophthalmol 1971, 71: 1206-11.

${ }^{33}$ Feeney-Burns L, Gao CL, Tidwell M: Lysosomal enzyme cytochemistry of human RPE, Bruch's membrane and Drusen. Invest Ophthalmol Vis Sci 1987, 28: 1138-47.

${ }^{34}$ Campochiaro PA, Jerdan JA, Glaser BM: The extracellular matrix of human retinal pigment epithelial cells in vivo and its synthesis in vitro. Invest Ophthalmol Vis Sci 1986, 27: 1615-21.

${ }^{35}$ Marshall J: The ageing retina: physiology or pathology. Eye 1987, 2: 282-95.

${ }^{36}$ Bird AC and Marshall J: Retinal receptor disorders without known metabolic abnormalities. In Pathobiology of Ocular Disease (A Garner and G Klintworth, eds), Dekker, New York: 1982, pp 1167-220.

${ }^{37}$ Runge P, Calver D, Marshall J, Taylor D: Histopath- 
ology of mitochondrial cytopathy and the Laurence-Moon-Biedl syndrome. Br J Ophthalmol 1986, 70: 782-96.

${ }^{38}$ Doweling JE and Sidman RL: Inherited retinal dystrophy in the rat. J Cell Biol 1962, 14: 73-109.

${ }^{39}$ Hewitt AT and Newsome DA: Altered synthesis of Bruch's membrane proteoglycans associated with dominant retinitis pigmentosa. Curr Eye Res 1985, 4: 169-74.

${ }^{41}$ Detrick B, Rodrigues M, Chan C-C, Tso M, Hooks $\mathrm{J}$ : Expression of HLA-DR antigen on retinal pigment epithelial cells in retinitis pigmentosa. $A m \mathrm{~J}$ Ophthalmol 1986, 101: 584-90.

${ }^{41}$ Boulton ME, McKenchnie NM, Breda J, Bayly M, Marshall J: The formation of autofluorescent granules in cultured RPE. Invest Ophthalmol Vis Sci 1989, 30: 82-9.

${ }^{42}$ Sidikarro Y, Trub PR, Morse LS: Formation of Drusen-like nodules by cultured RPE enhanced by UV irradiated rod outer segments. Invest Ophthalmol Vis Sci 1988, 29 (suppl): 2.

${ }^{4.3}$ Lawill T: Three major pathologic processes caused by light in the primate retina: A search for mechanisms. Trans Am Ophthalmol Soc 1982, 80: 517-79.

${ }^{44}$ Gouras P, Flood MT, Kjeldbye H: Transplantation of cultured human retinal cells to monkey retina. An Acad Brasil Cienc 1984, 56: 431-43.

${ }^{45}$ Lane CM and Boulton ME: Retinal pigment epithelial transplantation: technique and possible applications. In Patient Care in Retinitis Pigmentosa (R Gyzicki and F Brunsmann, eds) 1987, pp 125-38.

${ }^{46}$ Glaser BM: Extracellular modulating factors and the control of intraocular neovascularisation: An overview. Arch Ophthalmol 1988, 106: 603-7.

${ }^{47}$ Glaser BM, Campochiaro PA, Davis JL, Sato M: Retinal pigment epithelial cells release an inhibitor of neovascularisation. Arch Ophthalmol 1985, 103: $1870-5$.

${ }^{48}$ Wong HC, Boulton ME, McLeod D, Bayly M, Clark $\mathrm{P}$, Marshall J: Retinal pigment epithelial cells produce vascular mitogens. Arch Ophthalmol 1988, 106: $1439-43$. 